\title{
Proportions of Myosin Heavy Chain $m R N A s$, Protein Isoforms and Fiber Types in the Slow and Fast Skeletal Muscles Are Maintained After Alterations of Thyroid Status in Rats
}

\author{
T. SOUKUP ${ }^{1}$, M. DIALLO ${ }^{1}$ \\ ${ }^{1}$ Institute of Physiology, Academy of Sciences of the Czech Republic, Prague, Czech Republic
}

Received May 21, 2014

Accepted July 29, 2014

On-line September 5, 2014

\begin{abstract}
Summary
Recently, we have established that slow soleus (SOL) and fast extensor digitorum longus (EDL) muscles of euthyroid (EU) Lewis rats posses the same proportions between their four myosin heavy chain (MyHC) mRNAs, protein isoforms and fiber types as determined by real time RT-PCR, SDS-PAGE and 2-D stereological fiber type analysis, respectively. In the present paper we investigated if these proportions are maintained in adult Lewis rats with hyperthyroid (HT) and hypothyroid (HY) status. Although HT and $\mathrm{HY}$ states change MyHC isoform expression, results from all three methods showed that proportion between MyHC mRNA-1, $-2 a,-2 x / d,-2 b$, protein isoforms MyHC-1, $-2 a,-2 x / d,-2 b$ and to lesser extent also fiber types $1,2 \mathrm{~A}, 2 \mathrm{X} / \mathrm{D}, 2 \mathrm{~B}$ were preserved in both SOL and EDL muscles. Furthermore, in the SOL muscle $m R N A$ expression of slow $M y H C-1$ remained up to three orders higher compared to fast $M y H C$ transcripts, which explains the predominance of MyHC-1 isoform and fiber type 1 even in HT rats. Although HT status led in the SOL to increased expression of MyHC-2a $m R N A$, MyHC-2a isoform and 2A fibers, it preserved extremely low expression of $M y H C-2 x$ and $-2 b m R N A$ and protein isoforms, which explains the absence of pure $2 X / D$ and $2 B$ fibers. $\mathrm{HY}$ status, on the other hand, almost completely abolished expression of all three fast MyHC mRNAs, MyHC protein isoforms and fast fiber types in the SOL muscle. Our data present evidence that a correlation between $m R N A$, protein content and fiber type composition found in EU status is also preserved in $\mathrm{HT}$ and $\mathrm{HY}$ rats.
\end{abstract}

\section{Key words}

Thyroid hormones • Muscle gene expression, MyHC isoforms and muscle fiber types • Quantitative real time RT-PCR, SDS-PAGE and 2-D stereological analysis

\section{Corresponding author}

T. Soukup, Institute of Physiology, v.v.i., Academy of Sciences of the Czech Republic, Vídeňská 1083, 14220 Prague, Czech Republic. Fax: +420 224752488. E-mail: tsoukup@biomed.cas.cz

\section{Introduction}

Skeletal muscle fiber types are to the great extent defined by myosin heavy chain (MyHC) protein isoform composition, which is dependent on the specific MyHC $m R N A$ content and it was shown that in the rat both the EDL and SOL muscles express all four $M y H C-1$, $-2 a,-2 x / d$ and $-2 b m R N A s$ (Soukup et al. 2002, 2009, Smerdu and Soukup 2008, Zurmanova et al. 2008, Zurmanova and Soukup 2013, for review see Soukup and Jirmanová 2000, Schiaffino 2010). We have, however, recently shown that in the SOL muscle of adult Lewis rats, level of slow $M y H C-1 m R N A$ is up to three orders higher compared to fast MyHC mRNAs (Zurmanova and Soukup 2013). We also established that in EU Lewis rats both slow twitch SOL and fast twitch EDL posses the same proportions between their MyHC mRNAs, protein isoforms and fiber types determined by RT-PCR, SDS-PAGE and 2-D stereological fiber type analysis (Zurmanova and Soukup 2013). Thyroid hormones (TH) are known as powerful regulators of MyHC isoform expression and their altered levels are one of the important pathophysiological factors leading to $\mathrm{MyHC}$ transitions in cardiac and skeletal muscles. Both muscle types react to $\mathrm{TH}$ alteration by modifying their $M y H C$ $m R N A$ expression, protein isoform content and fiber type

PHYSIOLOGICAL RESEARCH • ISSN 0862-8408 (print) • ISSN 1802-9973 (online)

(c) 2015 Institute of Physiology v.v.i., Academy of Sciences of the Czech Republic, Prague, Czech Republic

Fax +420 241062 164, e-mail: physres@biomed.cas.cz, www.biomed.cas.cz/physiolres 
composition (Ianuzzo et al. 1977, d'Albis and ButlerBrowne 1993, Larsson et al. 1994, Caiozzo et al. 1997, Hudecova et al. 2004, Vadaszova and Soukup 2006a,b, Vadaszova-Soukup and Soukup 2007, Novák et al. 2010, Arnostova et al. 2011, for review see e.g. Schiaffino and Reggiani 1996, Pette et al. 1999, Soukup and Jirmanová 2000, Pette 2002, Vadaszova et al. 2004, Tribulova et al. 2010, Novák and Soukup 2011). TH as transcriptional factors acting via TH response element (Yen 2001) stimulate expression of fast genes and thus levels of fast MyHC isoforms and consequently fast fibers, while decreased TH levels lead to opposite changes.

The aim of the present paper was to analyze proportions in the expression of MyHC at $m R N A$ and protein levels as well as fiber type composition using real time RT-PCR, SDS-PAGE and 2-D stereological fiber type analysis of immunohistochemically stained muscle cross sections in the SOL and EDL muscles of adult HT and HY Lewis rats in order to answer the question if these proportions remain preserved in rats with altered TH status, similarly as was shown in EU rats (Zurmanova and Soukup 2013).

\section{Materials and Methods}

\section{Animals}

Experiments were performed on $9 \mathrm{HT}$ and $9 \mathrm{HY}$ adult (average age 14 months) inbred Lewis strain rats of both sexes obtained from the authorized rat-breeding unit of the Institute of Physiology, v.v.i., AS CR, Prague (Accreditation No. 1020/491/A/00). The maintenance and handling of experimental animals were in accordance with the 2010/63/EU Directive and the investigation was approved by the Expert Committee of the Institute of Physiology, v.v.i. Results of littermate EU animals were published earlier (Zurmanova and Soukup 2013) and are used in this paper for comparison with permission of Physiological Research journal. The animals were anesthetized with intraperitoneal injections of $1 \mathrm{ml}$ $(100 \mathrm{mg})$ of Narketan (Ketaminum ut hydrochloridum, Vetoquinol S.A., France) per $1000 \mathrm{~g}$ of body weight, followed by $0.5 \mathrm{ml}(10 \mathrm{mg})$ of the myorelaxant Xylapan (Xylazinum ut hydrochloridum, Vetoquinol Biowet, Poland) per $1000 \mathrm{~g}$ of body weight and sacrificed by exsanguination. The experimental muscles excised from hind limbs were frozen in liquid nitrogen, the right muscles were used for real time RT-PCR, while the left muscles were used to prepare cryocut sections or stored at $-80{ }^{\circ} \mathrm{C}$ until used for SDS-PAGE.

\section{Alteration of TH status}

HT or HY states were induced in 2-month-old animals and maintained for about 12 months by either intraperitoneal injections of 3,3',5-triiodo-L-thyronine (sodium salt, $\mathrm{T}_{3}, 0.15 \mu \mathrm{g} / \mathrm{kg}$ body weight) three times a week or with a $0.05 \%$ solution of methimazole (2-mercapto-1-methylimidazole) in drinking water, respectively. The EU rats were age-matched littermates of the HT and HY animals. The effect of our procedure was checked by measuring biochemical and anatomical parameters that are known to be influenced by TH level alterations (Soukup et al. 2001, Rauchová et al. 2004, 2011, 2013, Pavelka 2014).

$R N A$ isolation and quantitative real time $R T-P C R$ (qRT-PCR)

The primers described earlier (Zurmanova et al. 2007, 2008, Zurmanova and Soukup 2013) were designed using the Gene Runner program (Hastings Software). Total cellular RNA was extracted using the RNAzol RT (Sigma Aldrich), converted to cDNA using the RevertAid $^{\mathrm{TM}} \mathrm{H}$ Mius First Strand cDNA Synthesis Kit (Fermentas), samples of $1 \mu \mathrm{l}$ cDNA were amplified in $10 \mu 1$ of PCR reaction mixture containing $\mathrm{iQ}^{\mathrm{TM}}$ SYBR Green Supermix (Bio-Rad) and PCRs were performed on a Light Cycler (Roche Ltd.) (for a detailed description see Zurmanova et al. 2008, Zurmanova and Soukup 2013, Waskova-Arnostova et al. 2013).

\section{Immunohistochemistry}

Muscle fiber types were determined using mouse monoclonal antibodies (mAbs) specific for rat $\mathrm{MyHC}$ isoforms BA-D5 (MyHC-1), SC-71 (MyHC-2a), BF-35 (all MyHC except -2x/d) and BF-F3 (MyHC-2b) (Schiaffino 2010). Primary antibody binding was revealed using donkey secondary antibody conjugated with HRP (Jackson Immunoresearch Laboratories, USA) (for a detailed description see Smerdu and Soukup 2008, Soukup et al. 2009, 2012, Zurmanova and Soukup 2013).

\section{SDS-PAGE}

MyHC isoforms were separated according to Talmadge and Roy (1993) using MiniPROTEAN3 Cell

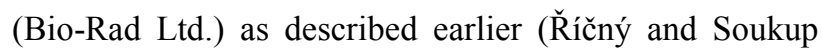
2011, Zurmanova and Soukup 2013). The silver-stained gels (Blum et al. 1987) were densitometrically evaluated using the LAS-1000 imaging system (Fujilab, Japan) and the AIDA 3.28 computer program at two gels from each sample. 


\section{Quantitative morphological analysis}

The numerical $(\mathrm{N})$ proportions (\%) of muscle fiber types were assessed by 2-D stereological methods using the principles of an unbiased counting frame and point counting (Zacharova and Kubínová 1995) using the C.A.S.T. Grid System (Olympus, Albertslund, Denmark). The particular arrangement of the stereological system (number of points, size of the counting frame, scanning interval) was selected according to muscle section size and fiber composition on the basis of efficacy analysis described previously (Zacharova and Kubínová 1995, Zacharova et al. 1997, 1999, 2005).

\section{Statistical analysis}

The data are expressed as mean \pm SE. Differences between individual $M y H C$ transcript level, MyHC protein isoform content and fiber type composition between $\mathrm{TH}$ states were evaluated using the Kruskal-Wallis One Way Analysis of Variance on Ranks (SigmaStat program, Systat Software, Germany).

\section{Results}

\section{The MyHC mRNAs analysis by qRT-PCR}

Our measurements revealed in the SOL muscles that the expression of faster $M y H C-2 a$ transcripts in HT status was significantly higher compared to HY (and EU) status (Fig. 1A). This increase was at the expense of slow $M y H C-1 m R N A$, because an increase of $M y H C-2 x / d$ was low (but significant) and $M y H C-2 b$ mRNA expression was negligible in both $\mathrm{HT}$ and $\mathrm{HY}$ status (Figs $1 \mathrm{~A}$ and 2A). Similarly as in the EU rats, the level of $M y H C-1$ $m R N A$ transcript was up to three orders higher than that of fast isoforms. On the other hand, HY status almost completely abolished expression of all three fast $m R N A s$ (Figs 1A and 2A) and thus the level of MyHC-1 mRNA expression was almost 2000 times higher compared to the $m R N A s$ of fast $M y H C$ isoforms (Fig. 1A).

The differences in expression among $M y H C$ transcripts in the EDL muscles were usually within the range of about one order. The highest expression levels in both HT and HY states (similarly as in EU status) showed fast $M y H C-2 b$ and $-2 x / d$ transcripts highly exceeding the levels of slower $M y H C-2 a$ and $M y H C-1$ transcripts (Figs $1 \mathrm{~B}$ and $3 \mathrm{~A}$ ). HT compared to HY (and EU) status significantly decreased the expression of slow $M y H C-1$ and $M y H C$-2a mRNAs, while HY status led to opposite changes. Transcript level of MyHC-2x/d was lower in HY compared to HT status, opposite to MyHC-2b transcript level (Figs 1B and 3A).

\section{The MyHC protein analysis by SDS-PAGE}

HT status in the SOL muscles compared to HY (and EU) status significantly increased content of MyHC-2a isoform and decreased that of MyHC-1 isoform, while traces (1 to $6 \%$ ) of MyHC-2x/d and/or of $-2 \mathrm{~b}$ isoforms found in some muscles were not significantly changed (Fig. 2B). On the other hand, HY status further increased the dominance of MyHC-1 and almost eliminated presence of fast isoforms including MyHC-2a (Fig. 2B).

In the EDL, HT status, compared to HY (and EU) status, significantly decreased content of MyHC-1 and -2a, while rather increased content of MyHC-2x/d and $-2 b$ isoforms (Fig. 3B). HY status lead to the opposite changes (Fig. 3B).

\section{Fiber type immunochemical analysis}

In the SOL muscles, HT status significantly decreased proportion of type 1 and increased that of $2 \mathrm{~A}$ (including hybrid 1/2A) fibers compared to HY (and EU) status, while HY status eliminated the presence of pure $2 \mathrm{~A}$ fibers (Fig. 2C) that were replaced by a variable low number of hybrid $1 / 2 \mathrm{~A}$ fibers stained by BA-D5 and SC-71 mAbs. All fibers in the SOL muscles in all TH states were stained by BF-35 mAb demonstrating the absence of pure $2 \mathrm{X} / \mathrm{D}$ fibers, furthermore no fibers were stained by BF-F3 $\mathrm{mAb}$ specifically recognizing $2 \mathrm{~B}$ fibers excluding presence of pure 2B fibers (Fig. 2C).
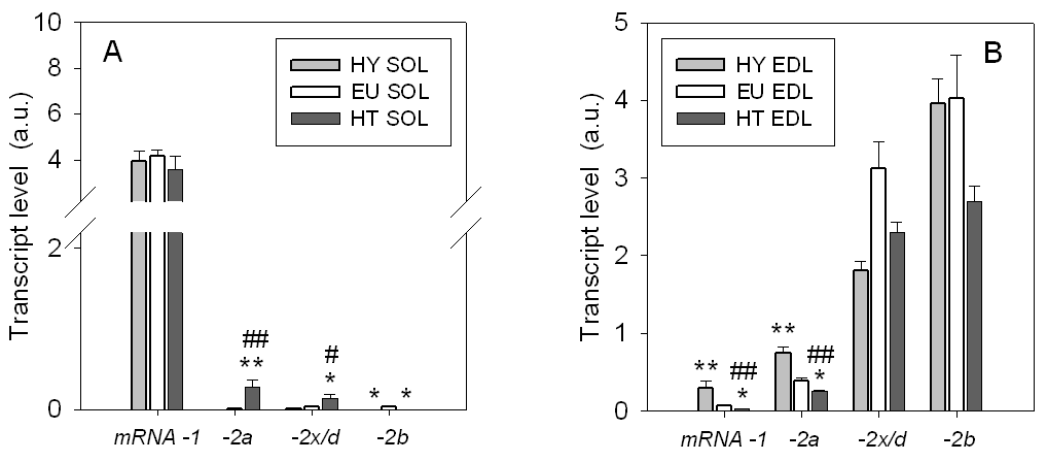

Fig. 1. A, B. Expression in arbitrary units (a.u.) of slow MYHC-1 mRNA (MYH7 gene) and fast MyHC-2a (MYH2 gene), MyHC-2x/d (MYH1gene) and MyHC-2b (MYH4 gene) mRNAs in the soleus (SOL) and the extensor digitorum longus (EDL) muscles of adult Lewis strain hypothyroid (hatched columns, HY), euthyroid (blank columns, EU) and hyperthyroid (dark column, $\mathrm{HT}$ ) rats. Note the great difference between MyHC-1 mRNA and fast MYH genes levels in the SOL compared to minor differences present in the EDL. Data for EU rats are from Zurmanova and Soukup (2013). Significantly different: ${ }^{\#} p \leq 0.05$, \#\# $p \leq 0.01$ vs. HY status, * $p \leq 0.05$, $* * p \leq 0.01$ vs. EU status. 

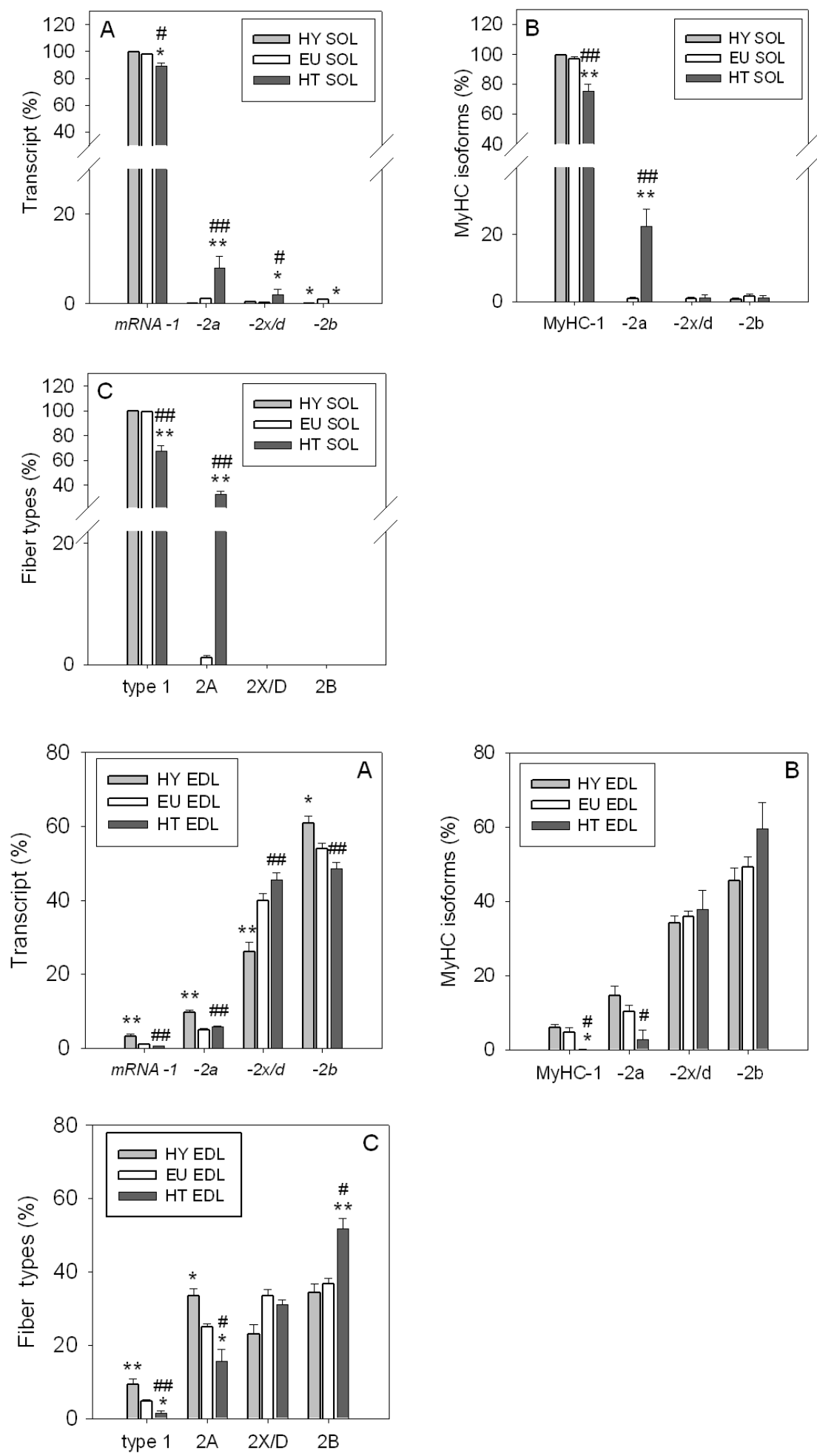

Fig. 2. A-C. Relative values (percentage) of slow MyHC-1 mRNA and fast MyHC-2a, $M y H C-2 x / d$ and $M y H C-2 b$ mRNAs expression as determined by qRT-PCR (Transcript), relative MyHC isoform content as determined by SDS-PAGE (MyHC isoforms) and fiber type proportions as determined by immunochemistry (Fiber types) in the soleus (SOL) muscles of adult Lewis strain hypothyroid (hatched columns, HY), euthyroid (blank columns, EU) and hyperthyroid (dark columns, HT) rats. Note the great difference in expression between the slow and fast MyHC MRNAs and corresponding differences in the MyHC content and fiber type proportion in all thyroid states. The close correlation between all three values indicates that $\mathrm{MyHC}$ isoform content and fiber phenotype are determined by gene expression and that changes observed in rats with altered thyroid status indicate regulation at the transcription level by the thyroid hormones. Data for EU rats are from Zurmanova and Soukup (2013). Significantly different: $\# p \leq 0.05, \quad \# p \leq 0.01$ vs. HY status, $* p \leq 0.05, * * p \leq 0.01$ vs. EU status.

Fig. 3. A-C. Relative values (percentage) of a slow MyHC-1 mRNA and fast MyHC-2a, $M y H C-2 x / d$ and MyHC-2b mRNAs expression as determined by qRT-PCR (Transcript), relative $\mathrm{MyHC}$ isoform content as determined by SDS-PAGE (MyHC isoforms) and fiber type proportions as determined by immunochemistry (Fiber types) in the extensor digitorum longus (EDL) muscles of adult Lewis strain hypothyroid (hatched columns, HY), euthyroid (blank columns, EU) and hyperthyroid (dark columns, HT) rats. Note that the difference between MyHC-1 and fast transcript levels, MyHC isoform content and fiber type proportions are much smaller compared to the soleus muscle. The close correlation between all three values indicates, similarly as in the soleus that MyHC isoform content and fiber phenotype are determined by gene expression and that changes observed in rats with altered thyroid status indicate regulation at the transcription level by the thyroid hormones. Data for EU rats are from Zurmanova and Soukup (2013). Significantly different: ${ }^{\#} p \leq 0.05,{ }^{\# \#} p \leq 0.01$ vs. HY status, $* p \leq 0.05, * * p \leq 0.01$ vs. EU status.
The number of the fastest $2 \mathrm{~B}$ fibers was significantly higher compared to $\mathrm{HY}$ (and EU) status in HT rats, while the number of $2 \mathrm{~A}$ and type 1 fibers was significantly lower (Fig. 3C). HY status, on the other hand, significantly increased the number of $2 \mathrm{~A}$ and type 1 fibers compared to HT (and EU) status and reduced the number of 2X/D and 2B (Fig. 3C) (for examples of immunohistochemical reactions see Zacharova et al. 2005, Soukup et al. 2012).

\section{Discussion}

Our results show for the first time that $\mathrm{TH}$ alterations induce corresponding changes in proportions 
of MyHC $m R N A s$, protein isoforms and fiber types in HY and HT rats, similarly as was recently described in EU rats (Zurmanova and Soukup 2013).

Comparison of MyHC $m R N A$, protein level and fiber type composition and the role of thyroid hormones

In the slow SOL muscles of adult HT and HY Lewis rats, similarly as in their EU littermates (Zurmanova and Soukup 2013), we identified all four MyHC-1, $-2 a,-2 x / d$ and $-2 b$ transcripts. The fast $M y H C-2 a,-2 x / d$ and $-2 b$ transcripts were, however, up to three orders lower than that of the slow $M y H C-1$ isoform, they were the lowest in HY, followed by EU and HT states. This finding correlated with the predominant content of MyHC-1 protein isoform supplemented by small amounts of fast $\mathrm{MyHC}$ protein isoforms, reflected by the absence of pure 2X/D and $2 \mathrm{~B}$ fibers. Alteration of $\mathrm{TH}$ level resulted in significant changes in $\mathrm{HT}$ status, when $M y H C-2 a m R N A$ expression, MyHC-2a content and percentage of $2 \mathrm{~A}$ fibers significantly increased. On the other hand, the increase of $M y H C-2 x / d m R N A$ compared to HY and EU states should be considered with caution because of the low expression levels. The results of immunochemical staining using BF-35 and BF-F3 mAbs showed that pure type $2 \mathrm{X} / \mathrm{D}$ and $2 \mathrm{~B}$ fibers were absent in the SOL muscles in HY and HT states, similarly as in EU status. Apparently, extremely low transcript and isoform contents are not sufficient to be represented at the phenotype level as $2 \mathrm{X} / \mathrm{D}$ and $2 \mathrm{~B}$ fibers. Although the level of all three fast transcripts was equally low, reflected by low levels of fast $\mathrm{MyHC}$ isoforms, $2 \mathrm{~A}$ and or hybrid $1 / 2 \mathrm{~A}$, but not $2 \mathrm{X} / \mathrm{D}$ and $2 \mathrm{~B}$, fibers could be detected in the majority of SOL muscles, many in HT, few in EU and exceptional in HY status. The minor increase of $M y H C-2 x / d m R N A$ expression in $\mathrm{TH}$ status did not result in increased synthesis of $\mathrm{MyHC}-2 \mathrm{x} / \mathrm{d}$ and appearance of $2 \mathrm{X} / \mathrm{D}$ fibers. However, as BF-35 mAb is a negative marker of $2 \mathrm{X} / \mathrm{D}$ fibers, even a small amount of MyHC-1 or $-2 \mathrm{a}$ can be stained and mask the possible existence of $2 \mathrm{X} / \mathrm{D}$ fibers.

The direct correlation between $m R N A$ level, MyHC protein isoform content and fiber type proportion was also revealed in the EDL muscles. The $m R N A$ $M y H C-2 b$ and $-2 x / d$ levels were about up to one order higher compared to $m R N A M y H C-1$ and even less when compared to $m R N A M y H C-2 a$ regardless TH status. The lowest amount of the $M y H C-1$ isoform transcript corresponds to a minor representation of slow MyHC-1 isoform and of slow type 1 fibers, which is fully in agreement with results of previous studies in Lewis strain rats (Soukup et al. 2002, 2009, Zacharova et al. 2005, Smerdu and Soukup 2008, Novák et al. 2010, Novák and Soukup 2011, Soukup et al. 2012). The amount of fast MyHC mRNAs increased in the same order as the content of $\mathrm{MyHC}$ protein isoforms and fiber type percentage i.e. type $1<2 \mathrm{a}<2 \mathrm{x} / \mathrm{d}<2 \mathrm{~b}$ in HT as well as in EU status. In HY status, this order was preserved in the case of $M y H C$ $m R N A$ and protein isoforms, while in the case of fiber types the percentage of $2 \mathrm{~A}$ fibers was higher than that of $2 \mathrm{X} / \mathrm{D}$ and the same as that of $2 \mathrm{~B}$ fibers. However, we suppose that due to high avidity of SC-71 antibody many fibers counted as $2 \mathrm{~A}$ fibers were in fact hybrid $2 \mathrm{~A} / \mathrm{X} / \mathrm{D}$ fibers (or even 2A/X/B). As expected, HT status increased MyHC content of the fastest $-2 b$ isoform as well as of corresponding $2 \mathrm{~B}$ fibers, while $\mathrm{HY}$ status increased the proportions of MyHC-1 and $-2 \mathrm{a}$ and of corresponding fiber types.

Three simultaneous analyses performed on the same group of animals showed that altered $\mathrm{TH}$ levels coordinately changed both $m R N A$ and MyHC protein levels, in most cases reflected by the subsequent change of corresponding fiber types. Compared to HY status, increased TH levels (HT status) resulted in a coordinated significant increase of $m R N A$ MyHC-2a, MyHC-2a isoform and $2 \mathrm{~A}$ fibers in the SOL and their decrease in the EDL. $M y H C-2 x / d$ and $-2 b m R N A$ changes were not reflected at protein and fiber levels in the SOL, while in the EDL the two fastest isoforms usually increased. As expected, HY status coordinately increased in both muscles the expression of $M y H C-1$ and $M y H C-2 a$ $m R N A s$, MyHC isoforms and corresponding fiber types and decreased that of faster isoforms (except $M y H C-2 b$ transcript).

\section{Conclusions}

Using three different methods we showed for the first time a direct correlation between transcript and $\mathrm{MyHC}$ isoform levels or fiber type proportions in corresponding muscle samples of euthyroid rats (Zurmanova and Soukup 2013). Our present results show for both SOL and EDL muscles an almost equivalent composition in percent of MyHC in the case $m R N A-1,-2 a,-2 x / d,-2 b$, MyHC-1, $-2 \mathrm{a}$, $-2 \mathrm{x} / \mathrm{d},-2 \mathrm{~b}$ protein isoforms and type $1,2 \mathrm{~A}, 2 \mathrm{X} / \mathrm{D}, 2 \mathrm{~B}$ fiber types in hyperthyroid and hypothyroid rats.

\section{Conflict of Interest}

There is no conflict of interest. 


\section{Acknowledgements}

The authors thank Ms. Dita Kašparová and Dr. Jitka Zurmanová for performing PCR, Ms. Martina Pytlová, Ms. Kateřina Kopecká and Ms. Anna Jokelová for fiber type determination, Dr. Stanislav Pavelka for determining thyroid hormone levels, Dr. Hana Rauchová for GPHD determination and Dr. Gisela Zacharova for statistical analysis. We also acknowledge that the monoclonal antibodies developed by Prof. Schiaffino were obtained from the Developmental Studies Hybridoma Bank developed under the auspices of the NICHD and maintained at The University of Iowa, Department of Biology, Iowa City, IA, USA. This study was supported by MYORES LSH-CT-2004-511978, GACR 304/08/0256, 7AMB12SK158 and 7AMB14SK123 grants and Research Project RVO: 67985823 (AV0Z 50110509). This work was also supported within the project The Centre of Biomedical Research (CZ.1.07/2.3.00/30.0025) co-funded by the European Social Fund and the state budget of the Czech Republic.

\section{References}

ARNOSTOVA P, JEDELSKY PL, SOUKUP T, ZURMANOVA J: Electrophoretic mobility of cardiac myosin heavy chain isoforms revisited: application of MALDI TOF/TOF analysis. J Biomed Biotechnol 2011: 634253, 2011.

BLUM H, BEIER H, GROSS HJ: Improved silver staining of plant-proteins, RNA and DNA in polyacrylamide gels. Electrophoresis 8: 93-99, 1987.

CAIOZZO VJ, BAKER MJ, MCCUE SA, BALDWIN KM: Single-fiber and whole muscle analyses of MHC isoform plasticity: interaction between T3 and unloading. Am J Physiol 273: C944-C952, 1997.

D'ALBIS A, BUTLER-BROWNE G: The hormonal control of myosin isoform expression in skeletal muscle of mammals: a review. BAM 3: 7-16, 1993.

HUDECOVA S, VADASZOVA A, SOUKUP T, KRIZANOVA O: Effect of thyroid hormones on the gene expression of calcium transport systems in rat muscles. Life Sci 75: 923-931, 2004.

IANUZZO D, PATEL P, CHEN V, O'BRIEN P, WILLIAMS C: Thyroidal trophic influence on skeletal muscle myosin. Nature 270: 74-76, 1977.

LARSSON L, LI X, TERESI A, SALVIATI G: Effects of thyroid hormone on fast- and slow-twitch skeletal muscles in young and old rats. $J$ Physiol 481: 149-161, 1994.

NOVAK P, SOUKUP T: Calsequestrin distribution, structure and function, its role in normal and pathological situations and the effect of thyroid hormones. Physiol Res 60: 439-452, 2011.

NOVAK P, ZACHAROVA G, SOUKUP T: Individual, age and sex differences in fiber type composition of slow and fast muscles of adult Lewis rats: comparison with other rat strains. Physiol Res 59: 783-801, 2010.

PAVELKA S: Development of radiometric assays for quantification of enzyme activities of the key enzymes of thyroid hormones metabolism. Physiol Res 63 (Suppl 1): S133-S140, 2014.

PETTE D: The adaptive potential of skeletal muscle fibers. Can J Appl Physiol 27: 423-448, 2002.

PETTE D, PEUKER H, STARON RS: The impact of biochemical methods for single muscle fibre analysis. Acta Physiol Scand 166: 261-277, 1999.

RAUCHOVA H, ZACHAROVA G, SOUKUP T: Influence of chronically altered thyroid status on the activity of liver mitochondrial glycerol-3-phosphate dehydrogenase in female inbred Lewis rats. Horm Metab Res 36: 286-290, 2004.

RAUCHOVA H, MRACEK T, NOVAK P, VOKURKOVA M, SOUKUP T: Glycerol-3-phosphate dehydrogenase expression and oxygen consumption in liver mitochondria of female and male rats with chronic alteration of thyroid status. Horm Metab Res 43: 43-47, 2011.

RAUCHOVA H, VOKURKOVA M, PAVELKA S, BEHULIAK M, TRIBULOVA N, SOUKUP T: N-3 polyunsaturated fatty acids supplementation does not affect changes of lipid metabolism induced in rats by altered thyroid status. Horm Metab Res 45: 507-512, 2013.

RICNY J, SOUKUP T: Comparison of new ELISA method with established SDS-PAGE method for determination of muscle myosin heavy chain isoforms. Physiol Res 60: 899-904, 2011.

SCHIAFFINO S: Fibre types in skeletal muscle: a personal account. Acta Physiol (Oxf) 199: 451-463, 2010. 
SCHIAFFINO S, REGGIANI C: Molecular diversity of myofibrillar proteins: gene regulation and functional significance. Physiol Rev 76: 371-423, 1996.

SMERDU V, SOUKUP T: Demonstration of myosin heavy chain isoforms in rat and humans: the specificity of seven available monoclonal antibodies used in immunohistochemical and immunoblotting methods. Eur J Histochem 52: 179-190, 2008.

SOUKUP T, JIRMANOVA I: Regulation of myosin expression in developing and regenerating extrafusal and intrafusal muscle fibers with special emphasis on the role of thyroid hormones. Physiol Res 49: 617-633, 2000.

SOUKUP T, ZACHAROVA G, SMERDU V, JIRMANOVA I: Body, heart, thyroid gland and skeletal muscle weight changes in rats with altered thyroid status. Physiol Res 50: 619-626, 2001.

SOUKUP T, ZACHAROVA G, SMERDU V: Fibre type composition of soleus and extensor digitorum longus muscles in normal female inbred Lewis rats. Acta Histochem 104: 399-405, 2002.

SOUKUP T, SMERDU V, ZACHAROVA G: Fiber type composition of unoperated rat soleus and extensor digitorum longus muscles after unilateral isotransplantation of a foreign muscle in long-term experiments. Physiol Res 58: 253-262, 2009.

SOUKUP T, SULIMENKO V, MARKOVA V, KOPECKA K, ZACHAROVA G, PALECEK J: Expression of the skeletal calsequestrin isoform in normal and regenerated skeletal muscles and in the hearts of rats with altered thyroid status. Physiol Res 61: 575-586, 2012.

TALMADGE RJ, ROY RR: Electrophoretic separation of rat skeletal muscle myosin heavy-chain isoforms. $J$ Appl Physiol 75: 2337-2340, 1993.

TRIBULOVA N, KNEZL V, SHAINBERG A, SEKI S, SOUKUP T: Thyroid hormones and cardiac arrhythmias. Vascul Pharmacol 52: 102-112, 2010.

VADASZOVA-SOUKUP A, SOUKUP T: Dual role of thyroid hormones in rat soleus muscle MyHC isoform expression. Physiol Res 56: 833-836, 2007.

VADASZOVA A, ZACHAROVA G, MACHACOVA K, JIRMANOVA I, SOUKUP T: Influence of thyroid status on the differentiation of slow and fast muscle phenotypes. Physiol Res $\mathbf{5 3}$ (Suppl 1): S57-S61, 2004.

VADASZOVA A, HUDECOVA S, KRIZANOVA O, SOUKUP T: Levels of myosin heavy chain mRNA transcripts and content of protein isoforms in the slow soleus muscle of 7-month-old rats with altered thyroid status. Physiol Res 55: 221-225, 2006a.

VADASZOVA A, HUDECOVA S, KRIZANOVA O, SOUKUP T: Levels of myosin heavy chain mRNA transcripts and protein isoforms in the fast extensor digitorum longus muscle of 7-month-old rats with chronic thyroid status alterations. Physiol Res 55: 707-710, 2006b.

WASKOVA-ARNOSTOVA P, ELSNICOVA B, KASPAROVA D, SEBESTA O, NOVOTNY J, NECKAR J, KOLAR F, ZURMANOVA J: Right-to-left ventricular differences in the expression of mitochondrial hexokinase and phosphorylation of Akt. Cell Physiol Biochem 31: 66-79, 2013.

YEN PM: Physiological and molecular basis of thyroid hormone action. Physiol Rev 81: 1097-1142, 2001.

ZACHAROVA G, KUBINOVA L: Stereological methods based on point counting and unbiased counting frames for two-dimensional measurements in muscles: comparison with manual and image analysis methods. $J$ Muscle Res Cell Motil 16: 295-302, 1995.

ZACHAROVA G, KNOTKOVA-URBANCOVA H, HNIK P, SOUKUP T: Nociceptive atrophy of the rat soleus muscle induced by bone fracture: a morphometric study. J Appl Physiol 82: 552-557, 1997.

ZACHAROVA G, MRACKOVA K, JIRMANOVA I, SOUKUP T: Stereological evaluation of the soleus muscle isografted into fast extensor digitorum longus (EDL) muscle in rats with different thyroid status. Gen Physiol Biophys 18 (Suppl 1): 84-86, 1999.

ZACHAROVA G, VADASZOVA A, SMERDU V, ASMUSSEN G, SOUKUP T: The effect of a unilateral muscle transplantation on the muscle fiber type and the MyHC isoform content in unoperated hind limb slow and fast muscles of the inbred Lewis rats. Physiol Res 54: 691-696, 2005.

ZURMANOVA J, SOUKUP T: Comparison of myosin heavy chain mRNAs, protein isoforms and fiber type proportions in the rat slow and fast muscles. Physiol Res 62: 445-453, 2013.

ZURMANOVA J, MALACOVA D, PUTA F, NOVAK P, RICNY J, SOUKUP T: Mass spectrometry analyses of rat 2b myosin heavy chain isoform. Physiol Res 56: 659-662, 2007. 
ZURMANOVA J, PUTA F, STOPKOVA R, SOUKUP T: Real time RT-PCR with a newly designed set of primers confirmed the presence of $2 \mathrm{~b}$ and $2 \mathrm{x} / \mathrm{d}$ myosin heavy chain mRNAs in the rat slow soleus muscle. Physiol Res 57: 973-978, 2008. 